\title{
Desenvolvimento de ensaio imunofluorométrico para a medida da globulina ligadora de tiroxina (thyroxine-binding globulin, TBG) e sua aplicação em casos de deficiência desta proteína
}

\author{
Development of an immunofluorometric assay for thyroxine-binding globulin (TBG) and its application in cases \\ of protein deficiency
}

\author{
José Gilberto H. Vieira ${ }^{1,2}$ \\ Teresinha T. Tachibana ${ }^{1}$ \\ Leda H. Obara' \\ Sônia K. Nishida ${ }^{2}$ \\ Maria Tereza Lombardi ${ }^{2}$ \\ Rui M.B. Maciel
}

\section{unitermos resumo}

Globulina ligadora de tiroxina

Ensaio imunofluorométrico

Deficiência congênita de TBG

Medida de tiroxina livre
A globulina ligadora de tiroxina (thyroxine-binding globulin, TBG) é a principal transportadora de hormônios tiroidianos no soro. Variações na concentração sérica de TBG determinam variações proporcionais nas concentrações séricas totais de T4 e T3, sem implicar alterações de função, desde que a fração livre permaneça normal. Várias condições clínicas comuns levam a alterações significativas nos níveis de TBG, sendo as variações mais importantes devidas a defeitos genéticos. Como a TBG é codificada por gene localizado no cromossomo $X$, os defeitos se manifestam mais facilmente no sexo masculino. Descrevemos o desenvolvimento de ensaio imunofluorométrico para a medida de TBG com base em anticorpos monoclonais, sendo um desenvolvido em nosso laboratório e outro comercial. O método apresenta sensibilidade de $0,8 \mathrm{mg} / \mathrm{l}$ e coeficientes de variação intra e interensaio inferiores a $10 \%$. O estudo comparativo com método comercial mostrou alta correlação $(r=0,93 ; n=48)$, sendo os valores normais obtidos de $10 \mathrm{mg} / \mathrm{l}$ a $29 \mathrm{mg} / \mathrm{l}$. Estudamos também 20 indivíduos portadores de deficiência congênita de TBG, 19 homens e uma mulher, que apresentavam valores normais de TSH e baixos de T4 total; em todos eles os níveis de TBG foram indetectáveis. Já os níveis de T4 livre medidos por método indireto em 16 desses indivíduos mostraram-se elevados em todos, ao passo que, quando medidos por método direto pós-diálise nos quatro restantes, mostraram-se normais. Nossos resultados reforçam a necessidade prática da disponibilidade de ensaio para a medida de TBG para esclarecimento e definição diagnóstica de alguns casos especiais, principalmente quando o ensaio de T4 livre direto, pós-diálise, não é disponível. 


\section{Introdução}

A globulina ligadora de tiroxina (TBG) é uma glicoproteína sintetizada pelos hepatócitos que apresenta peso molecular de 54kDa. A TBG é a principal responsável pelo transporte sérico dos hormônios tiroidianos tiroxina (T4) e triiodotironina (T3), sendo que $75 \%$ do primeiro e $70 \%$ do segundo encontram-se ligados à glicoproteína. Também participam deste transporte a pré-albumina ligadora de tiroxina (TBPA), ou transtiretina, que transporta $15 \%$ a $20 \%$ do T4, mas muito pouco T3, e a albumina. Em condições normais, apenas $0,03 \%$ do T4 e $0,3 \%$ do T3 encontram-se na forma livre.

As proteínas transportadoras de hormônios tiroidianos, e em especial a TBG, teriam como função a proteção do organismo contra variações bruscas dos níveis de hormônios tiroidianos, funcionando como reservatório circulante que libera os hormônios conforme as necessidades locais dos diferentes tecidos. Adicionalmente, em função de seu peso molecular, impedem a filtração glomerular dos hormônios tiroideanos a elas ligados, evitando sua perda urinária e protegendo o organismo contra uma possível deficiência de iodo (1).

Variações na concentração sérica de TBG determinam variações proporcionais das concentrações séricas totais dos hormônios tiroidianos, sem afetar a concentração dos hormônios livres, e, conseqüentemente, sem alterar a função tiroidiana. Várias condições comuns, como o uso de hormônios estrogênicos, gravidez e doenças sistêmicas graves, afetam significativamente a concentração de TBG. Outra condição onde os níveis podem estar profundamente alterados é nos defeitos hereditários da produção desta proteína. Estes últimos podem ser classificados de acordo com os níveis de TBG em: deficiência completa, deficiência parcial e excesso (1). Como a TBG é codificada por gene localizado no cromossomo X (Xq22.2) (2), os defeitos se manifestam completamente em hemizigotos do sexo masculino e parcialmente em heterozigotas. Nos casos de deficiência completa, a concentração sérica de TBG é indetectável, sendo a prevalência desta condição benigna em torno de 1:15.000 recém-nascidos do sexo masculino. Já a deficiência parcial é mais comum, com prevalência de 1:4.000 recém-nascidos, sendo a maior dificuldade a diferenciação entre as heterozigotas e os normais, desde que elas possam apresentar níveis de TBG compatíveis com os limites inferiores da normalidade. Quanto ao excesso de TBG, é uma condição mais rara, atingindo 1:25.000 recém-nascidos. Como nenhuma destas anomalias se acompanha de disfunção tiroidiana, o real papel da TBC tem sido muitas vezes questionado. A demonstração de que a TBG e a proteína ligadora de cortisol (CBG) fazem parte da família das proteínas inibidoras das serinoproteases (serpin) abriu novas perspectivas quanto ao papel fisiológico da TBG (3). Trabalhos recentes avaliaram este papel e levantaram a hipótese de que uma das funções da TBG seria a liberação de iodo nos locais onde existisse liberação de enzimas proteolíticas por leucócitos ativados $(4,5)$.

Neste trabalho apresentamos o desenvolvimento de um ensaio imunofluorométrico para a medida de TBC sérica e seu emprego na definição diagnóstica de pacientes com deficiência congênita na produção da proteína.

\section{Materiais e métodos}

\section{Anticorpos monoclonais}

Três camundongos balb/c foram imunizados com TBG purificada a partir de soro humano e fornecida por Scripps Laboratories, San Diego, CA, EUA. O animal com a meIhor resposta, avaliada por ensaio em que TBG foi adsorvida em fase sólida e a ligação de $\lg \mathrm{G}$ do camundongo revelada por anticorpo anti-lgG de camundongo ligado a peroxidase, foi escolhido para a fusão. Nesta empregamos esplenócitos do camundongo e células da linhagem de mieloma murino SP2/O, segundo técnica anteriormente descrita (6); a pesquisa de clones produtores foi feita com o mesmo ensaio imunoenzimático descrito acima. 0 anticorpo selecionado, em função da viabilidade da linhagem e de sua afinidade, foi o H6P9, IgG1, kappa; este anticorpo foi empregado como anticorpo de captura no ensaio. Como não obtivemos anticorpos com características compatíveis com o desenho de um ensaio imunométrico baseado no monoclonal H6P9, adquirimos o anticorpo M26211 (IgG2a) fornecido por Fitgerald Industries, Concord, MA, EUA, que apresenta a característica de ligar-se à TBG concomitantemente à ligação desta com o monoclonal H6P9, permitindo um desenho de ensaio imunométrico.

\section{Ensaios}

$\mathrm{O}$ ensaio desenvolvido emprega o monoclonal H6P9 adsorvido a placas de microtitulação (Maxisorp, Nunc A/S, Dinamarca), e o monoclonal M26211 marcado com európio (Europium Labelling Kit, Wallac Oy, Turku, 
Finlândia) como revelador. O tampão de ensaio é tris base- $\mathrm{HCl}$ com $5 \%$ de soro normal de camundongo. Como padrão empregamos TBG altamente purificada adquirida dos laboratórios Fitgerald. As amostras de soro são diluídas previamente a 1:25 em tampão de ensaio e $25 \mu \mathrm{l}$ são pipetados em cada poço, seguidos de $200 \mu \mathrm{l}$ de tampão de ensaio. Segue-se uma incubação inicial das amostras e padrões por duas horas à temperatura ambiente, seguida de lavagem, pipetagem de $200 \mu$ l de solução com o monoclonal marcado com európio e mais uma hora de incubação. Após nova lavagem adiciona-se o líquido de leitura (enhancing solution, Wallac) e a fluorescência é lida em fluorômetro tempo-sincronizado (Wallac). Como método comparativo empregamos o ensaio comercializado pela Perkin Elmer do Brasil, que é um ensaio competitivo baseado em monoclonal específico contra TBG e TBG marcada com európio. A faixa de normalidade para o método é de $13 \mathrm{mg} / \mathrm{l}$ a $36 \mathrm{mg} / \mathrm{l}$. Para a dosagem de T4 total empregamos método comercial fornecido por Perkin Elmer do Brasil, e para a dosagem de TSH empregamos ensaio imunofluorométrico desenvolvido em nosso laboratório (7), e que apresenta sensibilidade funcional de $0,03 \mathrm{mUI} / \mathrm{l}$. Quanto à dosagem de T4 livre, empregamos dois métodos. Um deles é o indireto, também fornecido pela Perkin Elmer, que é um ensaio em duas fases. $\mathrm{Na}$ primeira o soro entra em contato com o anticorpo antiT4 ligado à fase sólida; após lavagem, o T4 marcado com európio é acrescentado e ocupa os sítios de ligação do anticorpo não-ocupados pelo T4 da amostra. Desta maneira a ligação do traçador é inversamente proporcional ao nível de T4 livre da amostra. O outro método, empregado apenas nas quatro amostras, é o método direto pósdiálise (8), empregando reagentes fornecidos pelo Laboratório Nichols, San Juan Capistrano, CA, EUA. Este método é considerado referência, já que é pouco influenciado por alterações nas proteínas carregadoras (9).

\section{Amostras de soro}

Utilizamos para o estudo amostras de soro de nossa rotina diagnóstica dos últimos dois anos e amostras especiais anteriormente estudadas, em que foi detectada deficiência de TBG, e que permaneciam estocadas em nossa soroteca.

\section{Métodos estatísticos}

Para a comparação entre métodos e definição de faixa de normalidade empregamos o programa EP Evaluator (David G. Rhoads Associates, Inc., Kennet Square, PA, EUA).

\section{Resultados}

\section{Características do ensaio}

A concentração mínima detectável, nas condições definidas de volumes e diluições utilizadas, e calculada com base no perfil de imprecisão do ensaio, é de $0,8 \mathrm{mg} / \mathrm{l}$. O coeficiente de variação intra-ensaio, calculado com base na dosagem de uma amostra de soro de valor médio de $20,8 \mathrm{mg} / \mathrm{l}(n=20)$, foi de $7,4 \%$. O coeficiente de variação inter-ensaio, calculado com base numa amostra de soro com valor médio de 19,5mg/l, medida em 23 ensaios realizados ao longo de quatro meses, foi de $8,2 \%$. O estudo de paralelismo, realizado com a diluição seriada de uma amostra de soro com níveis elevados de TBG e diluída seriadamente em tampão de ensaio, mostrou recuperação média de $100 \%$. A determinação do nível de TBG em 35 amostras de soros de pacientes adultos de ambos os sexos com níveis normais de T4 total e de TSH, e que não faziam uso de drogas que pudessem alterar a função tiroidiana ou os níveis de TBG, mostrou valores entre $13 \mathrm{mg} / \mathrm{l}$ e $27 \mathrm{mg} / \mathrm{l}$, com média \pm desvio padrão de $17,8 \mathrm{mg} / \mathrm{l} \pm$ $3,3 \mathrm{mg} / \mathrm{l}$.

\section{Comparação com ensaio comercial}

Dosamos em paralelo, utilizando o método comercializado pela Perkin Elmer (Delfia) e o aqui descrito, os níveis de TBG em 48 amostras de soro procurando incluir todos os níveis encontrados na prática laboratorial. Os resultados obtidos estão representados na Figura, onde encontramos alto índice de correlação entre os dois métodos $(r=0,93)$. Os valores obtidos com nosso método foram significativamente mais baixos que os obtidos com o método comercial usado para comparação, com média \pm desvio padrão de $14,6 \mathrm{mg} / \mathrm{l} \pm 10 \mathrm{mg} / \mathrm{l}$ e $19,2 \mathrm{mg} / \mathrm{l} \pm$ $11,9 \mathrm{mg} / \mathrm{l}(p<0,0001)$, respectivamente. No cálculo do coeficiente de correlação segundo Deming obtivemos a equação $Y=0,85 X-1,93$, onde $Y$ corresponde ao resultado obtido com o método aqui descrito e $X$, com o método comercial. Com base nesta equação e levando-se em conta os valores de normalidade descritos para o método comercial, os valores críticos de normalidade para nosso método seriam entre $10 \mathrm{mg} / \mathrm{l}$ e $29 \mathrm{mg} / \mathrm{l}$.

\section{Valores encontrados em indivíduos com deficiência de TBC}

Os valores estão representados na Tabela. Um total de 20 amostras de soro foi estudado, sendo que, em todas, os 


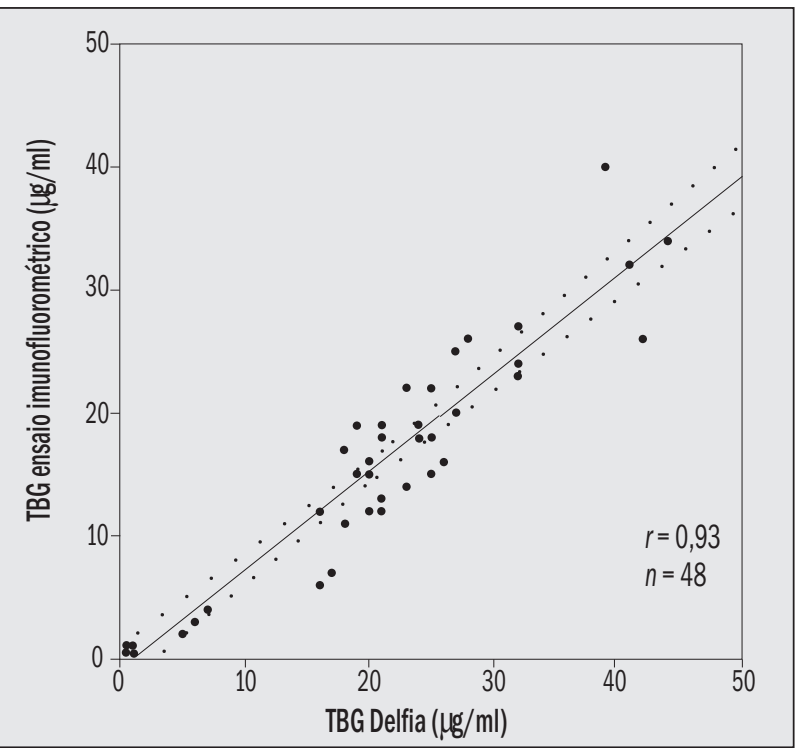

Figura - Correlação entre os resultados de TBG sérica obtidos com um ensaio comercial (Delfia) e com o ensaio descrito neste trabalho (ensaio imunofluorométrico)

níveis de TBG eram indetectáveis pelo método em estudo. Foram 19 indivíduos do sexo masculino e um do sexo feminino, sendo que oito dos indivíduos tinham menos de um ano de idade por ocasião do estudo. Em todos o valor de
TSH foi normal para a idade, com média \pm desvio padrão de $2,4 \mathrm{mUI} / \mathrm{I} \pm 1,3 \mathrm{mUI} / \mathrm{l} ;$ já os valores de $\mathrm{T} 4$ total foram abaixo do normal, com exceção de um indivíduo, com média \pm desvio padrão de $3 \mu \mathrm{g} / \mathrm{dl} \pm 0,7 \mu \mathrm{mg} / \mathrm{dl}$. A dosagem de $\mathrm{T} 4$ livre por método indireto foi realizada em 16 casos e em todos eles foram obtidos valores acima do normal para 0 método $(0,8 \mathrm{ng} / \mathrm{dl}$ a $1,5 \mathrm{ng} / \mathrm{dl})$, sendo a média de $2,3 \mathrm{ng} / \mathrm{dl} \pm$ $0,5 \mathrm{ng} / \mathrm{dl}$. Em quatro foi realizada a dosagem de T4 livre por método direto pós-diálise, e, nestes, os valores obtidos foram normais, variando de $1,4 \mathrm{ng} / \mathrm{dl} \mathrm{a} 1,9 \mathrm{ng} / \mathrm{dl}$.

\section{Discussão}

Variações nos níveis das principais proteínas carregadoras de hormônios tiroidianos podem ser congênitas ou adquiridas, sendo as alterações mais freqüentes aquelas que se referem aos níveis séricos de TBG (10). Pelo fato de alterações nos níveis séricos das proteínas transportadoras não implicarem alterações de função tiroidiana, mas poderem induzir alterações laboratoriais importantes, seu conhecimento e definição podem ter importância prática significativa. Apesar de os últimos consensos sobre a utili-

\section{Tabela}

\begin{tabular}{lccccc}
\hline Paciente & Sexo & Idade & T4 total & TSH & T4 \\
1 & M & $38 \mathrm{a}$ & 3,2 & 1,7 & 2,8 \\
2 & $\mathrm{M}$ & $5 \mathrm{a}$ & 3,2 & 2,1 & 3,4 \\
3 & $\mathrm{M}$ & $1 \mathrm{~m}$ & 2,5 & 2 & 2,8 \\
4 & $\mathrm{M}$ & $78 \mathrm{a}$ & 3,4 & 0,9 & 2,7 \\
5 & $\mathrm{M}$ & $4 \mathrm{~m}$ & 2,6 & 4,1 & \\
6 & $\mathrm{M}$ & $4 \mathrm{a}$ & 2,7 & 1,6 & 2,6 \\
7 & $\mathrm{M}$ & $52 \mathrm{a}$ & 2,2 & 1,1 & 1,7 \\
8 & $\mathrm{M}$ & $13 \mathrm{a}$ & 2,8 & 2,5 & 2,2 \\
9 & $\mathrm{M}$ & $49 \mathrm{a}$ & 3 & 1,1 & 2,2 \\
10 & $\mathrm{~F}$ & $28 \mathrm{a}$ & 3,2 & 3,9 & 1,6 \\
11 & $\mathrm{M}$ & $4 \mathrm{~m}$ & 2,4 & 5,8 & 1,9 \\
12 & $\mathrm{M}$ & $55 \mathrm{a}$ & 4,9 & 0,85 & 1,7 \\
13 & $\mathrm{M}$ & $1 \mathrm{~m}$ & 2,8 & 1,6 & 2,5 \\
14 & $\mathrm{M}$ & $3 \mathrm{a}$ & 3,1 & 2,3 & 2,1 \\
15 & $\mathrm{M}$ & $2 \mathrm{~m}$ & 1,9 & 2,7 & 1,9 \\
16 & $\mathrm{M}$ & $4 \mathrm{~m}$ & 2,6 & 4,1 & 2 \\
17 & $\mathrm{M}$ & $1 \mathrm{~m}$ & 2,5 & 3,3 & - \\
18 & $\mathrm{M}$ & $6 \mathrm{~m}$ & 3,5 & 3,2 & - \\
19 & $\mathrm{M}$ & $5 \mathrm{a}$ & 4,4 & 2,2 & - \\
20 & $\mathrm{M}$ & $32 \mathrm{a}$ & 3,1 & 1,2 & -
\end{tabular}

\section{Dados referentes aos indivíduos com deficiência congênita de TBG}

Valores normais para os métodos empregados (adultos): T4 total: 4,5 $\mathrm{gg} / \mathrm{dl}$ a $12 \mu \mathrm{g} / \mathrm{dl}$; TSH: 0,6mUI/l a 4,5mUI/l; T4 livre método indireto: 0,8ng/dl a 1,5ng/dl; T4 livre método direto pós-diálise: $0,8 \mathrm{ng} / \mathrm{dl} \mathrm{a} \mathrm{2,7ng/dl;} \mathrm{TBG:} 10 \mathrm{mg} / \mathrm{l}$ a $29 \mathrm{mg} / \mathrm{l}$. 
zação dos testes diagnósticos para avaliação de função tiroidiana serem unânimes em indicar a dosagem de TSH como o teste de referência (11), e a determinação de T4 livre como o teste complementar mais útil, a dosagem de T4 e T3 totais continua sendo empregada na prática diagnóstica. Num indivíduo com deficiência ou excesso de TBG, os valores das determinações de T3 e, principalmente, de T4 total podem apresentar distorções quantitativas grosseiras. Este aspecto pode ser particularmente importante em programas de detecção neonatal de hipotiroidismo que empregam a determinação de T4 total como teste único ou em conjunto com a determinação de TSH $(12,13)$. Crianças podem ser falsamente diagnosticadas como portadoras de hipotiroidismo e, pior, tratamento pode ser iniciado.

O método aqui descrito apresenta sensibilidade e características de precisão, exatidão e praticidade que o tornam elegível para uso diagnóstico. As características do ensaio são semelhantes aos obtidos com métodos equivalentes descritos na literatura (14), e os resultados, obtidos em indivíduos normais e em portadores de deficiência da proteína, dentro da faixa esperada e com alta correlação com os obtidos com ensaio competitivo obtido comercialmente.

Um fator complicador, do ponto de vista metodológico, na definição de normalidade de função tiroidiana em portadores de deficiência de TBG, é o fato de que os métodos indiretos para a medida de T4 livre, usados na grande maioria dos laboratórios, são influenciados pela ausência de TBG, levando a valores alterados de difícil interpretação. Estes valores podem ser falsamente elevados ou falsamen- te baixos, dependendo do tipo de anormalidade da concentração de TBG e do tipo de ensaio empregado para a medida de T4 livre $(9,15)$. Na casuística aqui apresentada de indivíduos com deficiência de TBG, todos tinham função tiroidiana normal, avaliada por níveis normais de TSH e, na maioria dos casos, pela avaliação clínica do médico assistente. No entanto, os níveis de T4 total eram grosseiramente diminuídos, o que levou em alguns casos a sérias dúvidas diagnósticas e mesmo a tratamentos indevidos. A determinação de T4 livre deveria resolver o problema, desde que a princípio ela fosse normal nesses indivíduos, mas quando realizada por método indireto resultou em valores falsamente elevados em todos os casos. A razão técnica para esta observação é o fato de que estes métodos indiretos são desenvolvidos levando-se em consideração a presença, no soro, de uma capacidade de ligação de tiroxina dentro da normalidade (16), fato que não ocorre em indivíduos com deficiência extrema de TBG como os casos aqui estudados. O emprego, em quatro casos, do método de referência para a medida de T4 livre, radioimunoensaio pós-diálise (8), resultou em valores normais, referendando a noção da normalidade de função tiroidiana nesses casos.

Em conclusão, apresentamos os resultados obtidos no desenvolvimento, e as características técnicas de um método imunofluorométrico para a medida de TBG sérica. Sua disponibilidade na rotina clínica mostrou-se de grande valia na definição diagnóstica em indivíduos com deficiência congênita de TBG, condição na qual os métodos de rotina para a medida de $\mathrm{T} 4$ livre e total levam a resultados conflitantes.

\section{Referências}

I. Refetoff, S. \& Nicoloff, J.T. Thyroid hormone transport and metabolism. In: De Groot, L.J. (ed). Endocrinology. Philadelphia:W.B. Saunders, 1995. v. I, p. 560.

2. Mori, Y. et al. Precise localization of the human thyroxinebinding globulin gene to chromosome $\mathrm{Xq} 22.2$ by fluorescence in situ hybridization. Human Genetics, 96:48I-2, 1995.

3. Flink, I.L. et al. Complete amino acid sequence of human thyroxine-binding globulin deduced from cloned DNA: close homology to the serine antiproteases. Proc Natl Acad Sci USA, 83: 7708-12, 1986

4. Jirasakuldech, B. et al. A characteristic serpin cleavage product of thyroxine-binding globulin appears in sepsis sera. J Clin Endocrinol Metab, 8: 3996-9, 2000.

5. Robbins, J. Editorial: new ideas in thyroxine-binding globulin biology.J Clin Endocrinol Metab, 85: 3994-5, 2000.
6. Vieira, J.G.H. et al. Monoclonal antibody-based immunofluorometric assay for human growth hormone. Brazilian J Med Biol Res, 23: 293-6, 1990.

7. Vieira, J.G.H. et al. Desenvolvimento e aplicação de um método imunofluorométrico para a dosagem de tirotrofina humana (TSH) no soro e em sangue total colhido em papel de filtro. Arq Bras Endocrinol Metab, 36: 7-12, 1992.

8. Nelson, J.C. \& Tomei, R.T. Direct determination of free thyroxine in undiluted serum by equilibrium dialysis/radioimmunoassay. Clin Chem, 34: 1737-44, 1988.

9. Nelson, J.C. et al. Dependence of free thyroxine estimates obtained with equilibrium dialysis on the concentration of thyroxine-binding globulin. Clin Chem, 38: 1294-300, 1992. 
10. Bartalena, L. \& Robbins, J. Variations in thyroid hormone transport proteins and their clinical implications. Thyroid, 2:237-45, 1992.

II. Spencer, C.A. et al. Current status and performance goals for serum thyrotropin (TSH) assays. Clin Chem, 42: I 40-5, 1996.

12. Mandel, S. et al.Thyroxine-binding globulin deficiency detected by newborn screening. J Pediatr, 122: 227-30, 1993.

13. Ward, L.S. et al. Comparação entre duas estratégias para a detecção precoce do hipotiroidismo congênito. Rev Ass Med Brasil, 44: 81-6, 1998.
14. Miyai, K. et al. Enzyme immunoassay of thyroxine-binding globulin. Clin Chem, 28: 2408- II, 1982.

15. Csako, G. et al. Direct and indirect techniques for free thyroxin compared in patients with nonthyroidal illness. II. Effect of prealbumin, albumin, and thyroxin-binding globulin. Clin Chem, 35: 1655-62, 1989.

16. Christofides, N.D. et al.Assessment of serum thyroxine binding capacity-dependent biases in free thyroxine assays. Clin Chem, 45: 520-5, 1999. 